\title{
Causal coherence and the availability of locations and objects during narrative comprehension
}

\author{
BRIAN A. SUNDERMEIER and PAUL VAN DEN BROEK \\ University of Minnesota, Minneapolis, Minnesota \\ and \\ ROLF A. ZWAAN \\ Florida State University, Tallahassee, Florida
}

\begin{abstract}
The aim of this study was to examine whether locations of objects are encoded and available to the reader at different points in a narrative, depending on their causal relevance. Participants in five experiments read narratives in which the spatial relation between an object and its location either did or did not provide a causal explanation for a later critical event. Object and location target words were presented to the participants immediately before or after the critical event. Speeded recognition response times to target words demonstrated that both locations and objects were reactivated, but only after they became causally relevant. The results suggest that the causal structure of a text can influence the availability of spatial information and that at least some spatial relations are encoded during reading and are available to the reader when they are needed to build coherence.
\end{abstract}

Comprehenders of a narrative can mentally represent many dimensions of the world described by a text, including spatial relations, temporal information, goals, and causal structure. With regard to the dynamics of the availability of spatial information during reading, especially concerning the locations of protagonists, the research findings have been inconsistent. Whereas some results suggest that readers do not keep track of detailed spatial information without special instructions to do so (Albrecht \& O’Brien, 1995; Hakala, 1999; Zwaan \& van Oostendorp, 1993, 1994), other results suggest that readers do keep track of spatial information even when not explicitly instructed to do so (Bower, Black, \& Turner, 1979; de Vega, 1995; Glenberg, Meyer, \& Lindem, 1987; Levine \& Klin, 2001; O’Brien \& Albrecht, 1992). To clarify these seemingly inconsistent results, it would be useful to discover the factors that contribute to the availability and maintenance of spatial information during regular reading (see Levine \& Klin, 2001; Zwaan \& Radvansky, 1998). In the experiments that follow, we tested whether the causal relevance of spatial information af-

This research was supported by the Golestan Foundation at the Netherlands Institute for Advanced Study in the Humanities and Social Sciences (NIAS), by the Guy Bond Endowment for Reading and Literacy, and by the Center for Cognitive Sciences at the University of Minnesota through Grant HD07151 from the National Institute of Child Health and Human Development. Portions of this article were presented at the 38th Annual Meeting of the Psychonomic Society, Philadelphia. We thank Rick Brown and Michelle Everson for helping to conduct portions of this study. Correspondence concerning this article should be addressed to P. van den Broek, Center for Cognitive Sciences, 205 Elliott Hall, 75 East River Road, University of Minnesota, Minneapolis, MN 55455 (e-mail: pvdbroek@umn.edu). fects the availability of previously mentioned locations and objects in a text.

Researchers generally agree that successful comprehension of a narrative entails representing a model of the situation described by the text (Graesser, Singer, \& Trabasso, 1994; Johnson-Laird, 1983, 1989; Perfetti, 1989; Radvansky \& Copeland, 2000; Radvansky, Zwaan, Curiel, \& Copeland, 2001; Zwaan, Langston, \& Graesser, 1995; Zwaan, Magliano, \& Graesser, 1995; Zwaan \& Radvansky, 1998). These situational representations are described as mental models (Johnson-Laird, 1983) or situation models (van Dijk \& Kintsch, 1983). The process of creating a situation model allows readers to understand things that are not explicitly stated in the text. In some instances, readers will draw inferences about the spatial relations between objects or the causal relation between events. For example, in comprehending the sentence "Three turtles were sitting on a $\log$ and a fish swam beneath them," readers routinely infer that the fish swam beneath the log (Bransford, Barclay, \& Franks, 1972). Similarly, during the construction of a situation model, readers may attempt to explain the causes of events as they proceed through a text (Fletcher, Hummel, \& Marsolek, 1990; van den Broek, 1990). For example, imagine a narrative in which the protagonist goes to the dentist one morning to get his wisdom teeth pulled. Later that night, his cheek is swollen. Drawing from a rich set of life experiences, a reader can easily infer that the character's visit to the dentist caused his cheek to be swollen. Comprehension of a passage therefore involves much more than the processing of individual sentences; it also involves the construction of a rich representation of the situation to which the text refers (Hess, Foss, \& Carroll, 1995). 
Another important aspect of the construction of situation models is its dynamic nature. Elements can fluctuate in terms of their availability in working memory as the reader proceeds through the text (Kintsch, 1988; Myers, O’Brien, Albrecht, \& Mason, 1994; van den Broek, Young, Tzeng, \& Linderholm, 1999). To a certain extent, fluctuations of elements depend on their function in the context of the narrative. For example, with respect to causal information, readers focus their attention on the last state or event that has causes but (as yet) no consequences in the preceding text (Fletcher et al., 1990). With respect to spatial representations, the proximity of an object to the protagonist in the world described by the story is sufficient to influence readers' representations. For example, readers keep an object more active in working memory when that object is on or near the main character than when it is distant from the main character (Glenberg et al., 1987). Findings such as these support the notion that a reader's efforts to construct a situation model on the basis of the text strongly affect the dynamic availability of causal and spatial information.

There is some debate as to whether spatial information plays a central role in a reader's representation during normal reading and to what extent it can influence the availability of objects. The results of some studies suggest that readers represent detailed spatial information, which, in turn, affects the availability of related items in memory (Morrow, Bower, \& Greenspan, 1989; Morrow, Greenspan, \& Bower, 1987; Morrow, Leirer, Altieri, \& Fitzsimmons, 1994; Rinck \& Bower, 1995; Wilson, Rinck, McNamara, Bower, \& Morrow, 1993). In these studies, the spatial distance between the protagonist and certain objects in the layout of the story affected the availability of those objects in a probe identification task, with response times being shortest when the objects were in the same room as the protagonist. In addition, participants are able to verify spatial relations from different characters' perspectives (de Vega, 1994). However, task demands and instructions likely play an important role in the maintenance of spatial information. In many of the studies mentioned above, readers were instructed to memorize the layout of a building or a description of a layout before reading a text about it. Apparently, the spatial model was formed before, rather than during, the reading of the text. Zwaan, Radvansky, Hilliard, and Curiel (1998), in a replication of Morrow et al.'s (1989; Morrow et al., 1987) studies, showed that only readers who had previously memorized the layout kept track of spatial changes in the story, whereas readers who had not previously memorized the layout did not do so. In other words, when the task requires readers to track spatial information, either by instructions or by the type of response task, it seems that they do so.

Additional research suggests that in the absence of explicit instructions to maintain spatial models, readers do not expend much effort to maintain them (Hakala, 1999; Zwaan \& van Oostendorp, 1993, 1994) and usually do not form spatial representations other than those explic- itly stated in the text (Langston, Kramer, \& Glenberg, 1998). Such failures in representing spatial information over the course of reading at times have been taken as evidence that readers do not form spatial models during normal reading. However, it seems reasonable that textual properties may encourage readers to develop spatial models and represent location information more fully. For instance, when reading about objects that are in different locations, readers have been shown to mentally update the representation of the protagonist's location if one of the objects is later mentioned by means of an anaphoric referent (de Vega, 1995). Also, readers immediately infer a change in the protagonist's location even in the absence of task demands if the location information is sufficiently elaborated (Levine \& Klin, 2001). In general, the lack of consistent findings of spatial influences during normal reading indicates the need for a guiding principle that can account for the different results and can predict when and how readers will use spatial information (Radvansky \& Copeland, 2000).

Our aim was to determine whether causality may influence the conditions under which readers represent spatial information during reading. There is considerable evidence that readers routinely represent the causal structure of events (see, e.g., Fletcher et al., 1990; Trabasso \& Magliano, 1996; Trabasso \& Suh, 1993; van den Broek, 1994; van den Broek \& Lorch, 1993). For example, readers judge events on the causal chain of events in a narrative as more important (Trabasso \& van den Broek, 1985) and recall them more frequently (Black \& Bower, 1980; Omanson, 1982; Trabasso \& van den Broek, 1985; Wolman \& van den Broek, 1993) than they do events that are not part of the main causal chain. In fact, the motivational and causal dimensions have been called the "backbone of situations constructed during narrative comprehension" (Zwaan \& Radvansky, 1998, p. 179) and readers will even search beyond the contents of working memory during reading to make global causal connections that build this "backbone" (Graesser et al., 1994). Because causal information is crucial for the comprehension of a narrative, it seems reasonable that spatial or location information is encoded and updated if it lies on the causal path of the narrative (Zwaan \& Radvansky, 1998; Zwaan, van den Broek, Truitt, \& Sundermeier, 1996). On the basis of the critical function of causality in narratives, we hypothesize that spatial relations are more available to a reader when they are used in an attempt to explain a critical event than when the same information is not needed to explain such events.

We tested this hypothesis, using a three-pronged approach, as suggested by Magliano and Graesser (1991). The first prong is for the use of theoretical models to develop materials possessing the desired properties. We used causal network theories (e.g., causal inference maker; Trabasso \& Sperry, 1985; van den Broek, 1990) to construct texts in which a critical event necessitated an explanation at a coherence break. In one version, particular spatial information was both necessary and sufficient for providing the explanation. According to the model, 
an inference incorporating the spatial information would be generated at the coherence break. In the other version, the same spatial information was not a part of the explanation, and the inference would not be generated. The second prong is empirical testing of the materials under ideal reading conditions - for example, by using a thinkaloud procedure (Experiment 1). Finally, the third prong is testing of the hypotheses with a speeded on-line paradigm. To test our hypotheses, we assessed the activation of location and object information in a series of response time experiments in order to discover whether readers actually encode and reinstate spatial information while reading. Experiments $2 \mathrm{~A}$ and $2 \mathrm{~B}$ were designed to test the availability of the location during on-line comprehension with a probe recognition task both before and after the critical event. In Experiments 3A and 3B, we similarly tested the availability of the object.

\section{EXPERIMENT 1}

A reader does not always come to a text with the same expectations, background knowledge, and mental alertness as at other times. Therefore, it is useful to discover what a reader is able to do and comprehend under the most ideal circumstances (Magliano \& Graesser, 1991). The purpose of the first experiment was to discover to what extent readers activate spatial/location information when given an unlimited time to read and think about each sentence as it relates to others. Using a think-aloud procedure, participants were instructed to read short narratives and to think aloud at the completion of each sentence (Ericsson \& Simon, 1998; Pressley \& Afflerbach, 1995). If the readers were encoding and later activating spatial information during the coherence break, one would expect that they would mention a specific object more often when reading the outcome sentence of a narrative in which the object and its location are causally relevant to that outcome than that of a narrative in which the object and its location are not causally connected to the outcome.

\section{Method}

Participants. Eighteen undergraduate students who were enrolled in an introductory psychology course at the University of Minnesota participated in this experiment. Extra credit in the course was given to each student for participation in the study. All the students spoke American English as their first language and had normal or corrected-to-normal vision.

Materials. Twelve short narratives consisting of inference situations depicting everyday life events were generated. Each story consisted of five sections: (1) an introduction giving general background information about characters, settings, and plot, (2) critical spatial information that included an object, a preposition (in, on, or by), and a location, (3) at least three sentences of filler material that was irrelevant to the spatial information, (4) a critical sentence describing the unexpected outcome, and (5) a continuation of the story if one is required for narrative flow. The mean length of the narratives was 16.5 sentences. Sentence complexity was almost exclusively limited to one-verb main clause constructions. Subordinate clauses were prepositional or adverbial phrases of five or fewer words.

There were two versions of each story, depending on the causal role of the spatial information. In the causally relevant (or experi- mental) version, the object, preposition, and location were causally connected to the outcome so that, taken together, they were necessary for the outcome to occur. In the noncausal (or control) version, the object and location were not causally connected to the outcome. Differences between the two versions were kept to a minimum. The Appendix contains an example of the narratives in both versions. The stories were constructed so that neither the object nor the location alone was causally sufficient to produce the outcome. Also, the texts were made in such a way as to avoid prompting forward inferences about the outcome before its actual occurrence and to separate the critical sentence from the outcome sentence by filler material.

Design. The 12 experimental stories were randomly divided into two sets of 6 . The participants were randomly assigned to one of the two sets. For each set of 6 stories, half of the participants received 3 stories in their causal version and 3 stories in their control version. The other half of the participants received the complement. The order of the narratives in the presentation phase was randomly determined for each participant.

Procedure. The participants were tested individually. They read the stories one sentence at a time from unlined index cards and were asked to verbalize aloud their thoughts for each sentence. A practice narrative preceded the 6 experimental stories. Prompts indicating the importance of talking were provided occasionally when there was silence for more than $10 \mathrm{sec}$. The participants' utterances were tape recorded throughout the duration of the study. Total testing time per individual was generally between 30 and $45 \mathrm{~min}$.

\section{Results}

An alpha level of .05 was used for all the statistical tests that follow. Effects were analyzed by participants $\left(F_{1}\right.$ or $\left.t_{1}\right)$ and by items $\left(F_{2}\right.$ or $\left.t_{2}\right)$. The average proportion of texts for which the object was mentioned at the critical point (the outcome) was greater in the causally relevant condition $(M=.47, S D=.135)$ than in the control condition $(M=.09, S D=.055)$ in an analysis by participants $\left[t_{1}(17)=11.12, p<.01\right]$ as well as in an analysis by items $\left[t_{2}(11)=3.75, p=.0015\right]$. The very small number of mentions in the control condition, along with the greater number of mentions in the causal version, supports the manipulation of the texts and furthermore suggests that readers, when given ample time and resources, reinstate object information only when this information is causally relevant by virtue of its spatial relation to the outcome of a story.

\section{EXPERIMENT 2A}

In Experiment 1, objects that were part of critical spatial information were mentioned in think-aloud protocols more often after the critical sentence in the causally relevant condition than in the control condition, suggesting that the readers reinstated object information when its spatial relations were causally important to the outcome sentence. In the next two experiments, we investigated whether readers encode location information during unprompted reading and whether they make inferences about spatial information when it is causally relevant to the text. In Experiment 2A, a probe word representing the spatial location of the object was presented to the participants immediately after the critical or outcome sentence - the point at which an inference involving the location would provide a causal explanation for the out- 
come in the experimental condition. The participants were instructed to indicate as quickly and accurately as possible whether the target word had been encountered previously in the text. Response times and accuracy to the target were recorded. If readers use location information in causal explanations about a surprising event and if location information is accessible to the reader as he/she is processing the outcome, the participants' responses to the probe word would be faster and/or more accurate for the causally relevant version of text than for the control version. If readers do not make inferences about location or do not have access to this information, there would be no significant difference in the response time and accuracy to the probe word between the two conditions.

\section{Method}

Participants. Thirty-seven undergraduate students taking an introductory psychology class at the University of Minnesota participated in this experiment for extra credit. All the participants spoke American English as their first language and had normal or correctedto-normal vision.

Materials. The materials were the same as those in Experiment 1 . The location words were presented as targets. In addition to the 12 experimental stories, 12 filler stories similar in length and style were constructed and matched with a target word that did not occur in the text.

Design. Each participant read the 12 experimental stories and 12 filler items. Because each participant saw a particular story only in either the causally relevant version or the control version during the on-line task, the stories were randomly assigned to two lists each containing six causal versions and six noncausal versions. Both lists of stories were counterbalanced across participants. The order of stories was randomly determined for each participant.

Apparatus. Stimulus presentation and data collection were controlled by an IBM PC utilizing Micro Experimental Laboratory Version 2.0 software (Psychology Tools Inc.). Presentation of the text was self-paced, and responses were made on a four-button response box accurate to within $1 \mathrm{msec}$.

Procedure. The participants were told that they were participating in an experiment involving comprehension of text. They were instructed to read each text at their own normal reading rate and were told that each text reading would be followed by two tasks: a recognition task and a comprehension task. After these tasks had been explained, the participants completed a practice trial. If problems were noted, the instructions were clarified, and another practice trial was completed.

Each participant placed his or her left-hand index finger over the leftmost button of a four-button response box and his or her right-hand index finger and right-hand second finger over the two rightmost buttons. Each story was presented in the vertical center of the screen, one clause at a time. The participants advanced lines of text by pressing the leftmost button of the buttonbox with the left index finger. Immediately after reading the critical sentence in the experimental stories, the participants made speeded recognition judgments to the target word. A row of five asterisks appeared in the center of the screen for $500 \mathrm{msec}$ and was immediately replaced by a word. The participants indicated whether they had seen this word previously in the story. For half of the trials, the word appeared in the story, and for the other half of the trials (i.e., for the filler stories), the word did not appear. To ensure that the decision task was not trivial, the filler words were balanced in length and word frequency with the target words (see Kučera \& Francis, 1967) and were constructed so that they were related to a word in the story.
The participants made yes responses with the right index finger and no responses with the second finger of the right hand. The participants were instructed to respond as quickly as possible to the word while being as accurate as possible. Immediate accuracy feedback was given for $1,000 \mathrm{msec}$. Response times from the onset of the target word and accuracy rates were recorded. After the participants had finished reading each story, they were presented with a yes/no comprehension question to prevent superficial understanding and strategic responses to the probe task. Feedback was given in the same manner as for the target word. An example question is presented in the Appendix. The participants read 24 stories - 6 experimental, 6 control, and 12 fillers - and completed the experiment in an average of $35 \mathrm{~min}$.

\section{Results}

The participants' response times and accuracy rates were the dependent variables of interest in this experiment. All data from any participant who experienced difficulties with the computer program were excluded from the analysis. Response times were analyzed separately by condition, and all data points faster than $200 \mathrm{msec}$ and all incorrect responses were eliminated. A cutoff was established in which $2.5 \%$ of the longest response times for correct responses in each condition were removed (see Ratcliff, 1993). When more than $75 \%$ of a participant's or an item's scores were removed, the entire set of scores for that participant or item was not considered.

Table 1 presents mean accuracy rates and mean response times to the probe words. Response times to the probe word were significantly shorter in the causally relevant condition than in the control condition $\left[F_{1}(1,36)=\right.$ $5.33, M S_{\mathrm{e}}=29,737, p=.03 ; F_{2}(1,11)=4.87, M S_{\mathrm{e}}=$ $10,709, p=.05]$. Accuracy rates between the experimental condition and the control condition did not differ statistically (both $F \mathrm{~s}<1$ ). Accuracy rates to the comprehension questions in the causally relevant condition $(M=87 \%, S D=0.18)$ did not differ statistically from those in the control condition $(M=84 \%, S D=0.17$; both $F \mathrm{~s}<1$ ).

Table 1

Mean Response Times (in Milliseconds) and Mean Accuracy Rates for Probe Words in Experiments 2 and 3

\begin{tabular}{|c|c|c|c|c|}
\hline \multirow[b]{2}{*}{ Experiment } & \multicolumn{2}{|c|}{ Experimental } & \multicolumn{2}{|c|}{ Control } \\
\hline & $M$ & $S D$ & $M$ & $S D$ \\
\hline \multicolumn{5}{|c|}{ Response Times } \\
\hline \multicolumn{5}{|l|}{ Location probe } \\
\hline After outcome (2A) & 1,220 & 290 & 1,312 & 317 \\
\hline Before outcome (2B) & 1,296 & 287 & 1,307 & 303 \\
\hline \multicolumn{5}{|l|}{ Object probe } \\
\hline After outcome (3A) & 1,119 & 226 & 1,208 & 260 \\
\hline Before outcome (3B) & 1,207 & 240 & 1,203 & 241 \\
\hline \multicolumn{5}{|c|}{ Accuracy Rates } \\
\hline \multicolumn{5}{|l|}{ Location probe } \\
\hline After outcome (2A) & .86 & .19 & .88 & .13 \\
\hline Before outcome (2B) & .90 & .22 & .87 & .23 \\
\hline \multicolumn{5}{|l|}{ Object probe } \\
\hline After outcome (3A) & .94 & .25 & .94 & .27 \\
\hline Before outcome (3B) & .95 & .23 & .94 & .25 \\
\hline
\end{tabular}




\section{EXPERIMENT 2B}

In the previous experiment, the location probe word was more highly activated in the causal version than in the control immediately after the outcome sentence, suggesting that an inference about the spatial information had been made. These results are in accord with those from Experiment 1. It is possible, however, that these results are caused not by inference generation but by differences in the extent to which location information was activated after its initial introduction but before the target statement. Experiment 2B was designed to test this possibility: Here, the probe word was presented immediately before the outcome sentence. If the causally relevant and the control conditions in Experiment 2A differed in the maintenance or prior activation of location after it had been mentioned in the text, the response to the location probe would be faster and/or more accurate in the causally relevant condition than in the control condition. In contrast, if there was no differential activation prior to the outcome statement, there would be no significant differences in response time and accuracy for the target word between the control and the causally relevant versions of the story.

\section{Method}

Participants. Thirty-eight undergraduate students taking an introductory psychology class at the University of Minnesota participated in this experiment for extra credit. All the participants spoke American English as their first language and had normal or correctedto-normal vision.

Materials. The materials were identical to those in Experiment 2A.

Design and Apparatus. The design and apparatus were identical to those in Experiment 2A.

Procedure. The procedure was the same as the one in Experiment $2 \mathrm{~A}$, except that the probe word was presented before the critical sentence instead of after it.

\section{Results}

Table 1 presents the mean accuracy rates and mean response times to the probe words. Neither response times nor accuracy rates differed significantly between conditions in either the subjects analysis or the items analysis (all $F \mathrm{~s}<1$ ). Thus, there was no evidence that location information was reactivated or maintained prior to the outcome sentence. Accuracy rates for the comprehension questions in the causally relevant condition $(M=$ $91 \%, S D=0.14$ ) did not differ statistically from those in the control condition $(M=89 \%, S D=0.15$; both $F \mathrm{~s}<$ 1). To confirm that the pattern of response time results differed between Experiments 2A and 2B (targets presented after and before the outcome, respectively), the data from both experiments were analyzed together, with experiment as the between-subjects factor. The interaction between causal condition and experiment was significant in an analysis by participants $\left[F_{1}(1,73)=3.82\right.$, $M S_{\mathrm{e}}=16,517, p=.05 ; F_{2}(1,22)=2.06, M S_{\mathrm{e}}=9,458$, $p=.17]$, indicating that response times for location information were shorter in the causally relevant condition than in the control condition only after a causal explanation inference had been generated (Experiment 2A). ${ }^{1}$

\section{EXPERIMENT 3A}

The results from Experiments $2 \mathrm{~A}$ and $2 \mathrm{~B}$ reflect differences in the processing of location between the causal and the noncausal conditions. Specifically, the participants responded more quickly to the location probe after-but not before - reading the outcome sentence when it was causally relevant to that outcome than they did in the control condition. This suggests that the location word was reinstated when it was necessary to provide a causal explanation for the critical outcome sentence. By implication, this means that the location had originally been encoded.

Experiments 3A and 3B addressed the issue of whether the object was reinstated. On the basis of our hypothesis that the object and the location are connected in the situation model, one would expect patterns similar to those observed for locations in Experiments 2A and 2B. In Experiment $3 \mathrm{~A}$, the object probe word was presented to the participants after the outcome sentence. If readers make inferences relevant to object information only when it is causally relevant to the outcome, the participants' response times to the target words would be shorter in the causally relevant version of a text than in the control version. In contrast, if readers do not reinstate the object or do not encode the object information, there would be no difference in response times between the two conditions.

\section{Method}

Participants. Forty-one undergraduate students taking an introductory psychology class at the University of Minnesota participated in this experiment for extra credit.

Materials. The materials were the same as those in Experiments $2 \mathrm{~A}$ and $2 \mathrm{~B}$, with the exception that the object words were used as targets.

Procedure. The procedure was identical to that used in Experiments $2 \mathrm{~A}$ and $2 \mathrm{~B}$.

\section{Results}

Table 1 presents the mean accuracy rates and mean response times to the probe word. Response time to the probe word was significantly shorter in the causally relevant condition than in the control condition $\left[F_{1}(1,40)=\right.$ $11.29, M S_{\mathrm{e}}=14,309, p=.002 ; F_{2}(1,11)=6.08, M S_{\mathrm{e}}=$ $6,876, p=.03]$. Accuracy in the experimental condition was not significantly greater than accuracy in the control condition (both $F \mathrm{~s}<1$ ). Accuracy rates to the comprehension questions in the causally relevant condition $(M=$ $90 \%, S D=0.13$ ) did not differ statistically from those in the control condition $(M=91 \%, S D=0.12$; both $F \mathrm{~s}<1)$.

\section{EXPERIMENT 3B}

In Experiment $3 \mathrm{~A}$, the object probe word was presented before the outcome sentence. If the experimental and the control conditions in Experiment 2A differed in the maintenance or prior activation of the object after it had been mentioned in the text, the response to the object probe would be faster and/or more accurate in the causally relevant condition than in the control condition. 
In contrast, if there was no differential activation prior to the target, there would be no significant differences in response time and accuracy for the target word between the control and the causally relevant versions of the story.

\section{Method \\ Participants. Forty-three undergraduate students taking an in- troductory psychology class at the University of Minnesota partic- ipated in this experiment for extra credit. \\ Materials. The materials were the same as those in Experiment 3A. \\ Procedure. The procedure was identical to the one used in Ex- periment $3 \mathrm{~A}$, except that the probe word was presented before the critical sentence instead of after it.}

\section{Results}

Table 1 presents the mean accuracy rates and mean response times to the probe word. Neither speed nor accuracy of responses to the probes differed significantly between conditions, either by subject analysis or by item analysis (both $F_{\mathrm{s}}<1$ ). Thus, there was no evidence that objects were reactivated or maintained prior to the outcome sentence. Accuracy rates to the comprehension questions in the causally relevant condition $(M=93 \%$, $S D=0.12$ ) did not differ statistically from those in the control condition $(M=94 \%, S D=0.10$; both $F \mathrm{~s}<1)$. Causal condition interacted with experiment in the combined analyses of Experiments $3 \mathrm{~A}$ and $3 \mathrm{~B}\left[F_{1}(1,82)=\right.$ $6.31, M S_{\mathrm{e}}=14,410, p=.014 ; F_{2}(1,22)=2.66, M S_{\mathrm{e}}=$ $7,542, p=.12]$, indicating that response times for object information were shorter in the causally relevant condition than in the control condition, but only after a causal explanation inference had been generated. Furthermore, a one-tailed $t$ test comparison of response times in the causally relevant condition revealed that response times to object target words presented after the outcome sentence were significantly shorter than response times to targets presented immediately before the outcome sentence in an analysis by participants $\left(t_{1}=1.73, p=.04\right)$. The results of Experiments $3 \mathrm{~A}$ and $3 \mathrm{~B}$ demonstrate that an object is reinstated after-but not before-an outcome sentence only when it provides a causal explanation for the outcome. Thus, the results for objects parallel those obtained for locations. Both are encoded during reading and are available for later processing. Furthermore, they are reinstated at a later point in the text when and only when they are causally relevant.

\section{GENERAL DISCUSSION}

The results from five experiments demonstrate that during reading, information concerning spatial relations is reactivated when needed for causal coherence. The results of Experiments 2B and 3B suggest that these activations were indeed reactivations. They were not the result of simple maintenance in working memory: Neither object nor location was activated prior to the outcome sentence. Furthermore, the fact that object and location information was reinstated implies that the association was encoded at some level during initial reading. This spatial association was accessible during reading of the remainder of the narrative, although it was reactivated only when needed for coherence.

It is conceivable that activation of the targets in the experimental condition (when probed after the critical sentence) could have been obtained if there had been maintenance of the spatial information before the critical sentence. In the present study, the relation between object and location (i.e., the ticket stub in Mark's pocket) could have remained more available (than neutral information), given that it might have been considered an unfulfilled goal or condition with consequences. Such maintenance has been observed for unsatisfied goals, resulting in a greater availability of these goals, relative to completed goals (Lutz \& Radvansky, 1997). However, this possibility did not extend to the spatial information in our studies. In Experiments 3A and 3B, the participants responded significantly more slowly to object targets presented before the outcome than to those presented after the outcome. This pattern of results does not support an interpretation that the objects related to an unfulfilled goal were continuously maintained in memory until the critical outcome, promoting shorter response times to the target. Furthermore, in those experiments in which the participants were probed with the target before the outcome sentence (2B and 3B), response times to targets in the control and the causally relevant conditions did not differ. This also suggests that the spatial information (potential unfulfilled goal) was not maintained immediately prior to the outcome, or else one would have expected to observe shorter response times to the probe in the causal condition, relative to the control condition.

Another possible explanation is that our results reflect decreased availability of the spatial information in the control texts, rather than increased availability of the spatial information in the experimental texts. ${ }^{2}$ With respect to goals, for instance, Lutz and Radvansky (1997) observed that failed goal information remained more available than completed goal information and concluded that this was due to "both an increased availability of failed goal information and a decreased availability of completed goal information (relative to failed goal information)" (p. 308). Additional evidence has supported the notion that readers suppress irrelevant information during reading (e.g., Gernsbacher \& Faust, 1991; Gernsbacher, Keysar, Robertson, \& Werner, 2001; Linderholm et al., 2004). Therefore, it is possible that the outcome sentence in the control condition in these experiments might have led the reader away from thinking about the target spatial information because it was no longer relevant, decreasing its availability. However, there was a negligible difference between responses to the object and location probes before versus after the outcome in the control versions of the text. ${ }^{3}$ Therefore, suppression alone does not adequately account for the results in the present study, because there was no decrease in availability of location and object information in the control text versions. 
Our results and interpretations are consistent with existing models of text comprehension. For example, the conclusion that spatial information may be encoded and may be retrievable at later points in reading without having been maintained in short-term memory is compatible with notions of long-term working memory (Ericsson \& Kintsch, 1995) and of implicit focus on information connected to the protagonist in a story (Garrod \& Sanford, 1990), and with resonance theories of text representation and retrieval (Myers \& O'Brien, 1998; O’Brien, Raney, Albrecht, \& Rayner, 1997). Indeed, of the many dimensions of textual information that readers may track during reading, spatial information is most likely to be encoded at relatively low levels (Zwaan, Langston, \& Graesser, 1995). The finding that this information is reactivated when needed for coherence is compatible with other models of comprehension, such as the landscape model, in which the activation of information at each point during reading is a function of the current text input, the strength of encoding of earlier information, and-relevant to the present study - the function that information fulfills in establishing coherence (van den Broek et al., 1999).

The conclusion that causal relevance determines the reactivation of previously read spatial information allows us to better answer the question concerning the circumstances in which readers represent and update spatial information while reading a text. Whereas instructions and reader goals can influence the availability of spatial information, it is also likely that the functionality of spatial information in a text can influence its availability. According to the functionality principle, readers are more likely to incorporate spatial information into their situation models if the spatial relations are functional (Radvansky \& Copeland, 2000; see also Carlson-Radvansky \& Radvansky, 1996). In accord with these earlier findings, our results suggest that in the absence of certain specific instructions or goals, nonelaborated spatial information is reactivated during reading only if it is functional-for instance, when it establishes causal coherence.

\section{REFERENCES}

Albrecht, J. E., \& O'Brien, E. J. (1995). Goal processing and the maintenance of global coherence. In R. F. Lorch \& E. J. O'Brien (Eds.), Sources of coherence in reading (pp. 263-278). Hillsdale, NJ: Erlbaum.

BLACK, J. B., \& Bower, G. H. (1980). Story understanding as problem solving. Poetics, 9, 223-250.

Bower, G. H., BLACK, J. B., \& Turner, T. J. (1979). Scripts in memory for text. Cognitive Psychology, 11, 177-220.

Bransford, J. D., Barclay, J. R., \& Franks, J. J. (1972). Sentence memory: A constructive versus interpretive approach. Cognitive Psychology, 3, 193-209.

Carlson-Radvansky, L. A., \& Radvansky, G. A. (1996). The influence of functional relations on spatial term selection. Psychological Science, 7, 56-60.

DE VeGa, M. (1994). Characters and their perspectives in narratives describing spatial environments. Psychological Research, 56, 116-126.

DE VEGA, M. (1995). Backward updating of mental models during continuous reading of narratives. Journal of Experimental Psychology: Learning, Memory, \& Cognition, 21, 373-385.

ERICsSON, K. A., \& KinTsCH, W. (1995). Long-term working memory. Psychological Review, 102, 211-245.
Ericsson, K. A., \& Simon, H. A. (1998). How to study thinking in everyday life: Contrasting think-aloud protocols with descriptions and explanations of thinking. Mind, Culture, \& Activity, 5, 178-186.

Fletcher, C. R., Hummel, J. E., \& Marsolek, C. J. (1990). Causality and the allocation of attention during comprehension. Journal of Experimental Psychology: Learning, Memory, \& Cognition, 16, 233240.

GaRrod, S. C., \& SANFORD, A. J. (1990). Referential processes in reading: Focusing on roles and individuals. In D. A. Balota, G. B. Flores d'Arcais, \& K. Rayner (Eds.), Comprehension processes in reading (pp. 465-486). Hillsdale, NJ: Erlbaum.

Gernsbacher, M. A., \& Faust, M. (1991). The mechanism of suppression: A component of general comprehension skill. Journal of Experimental Psychology: Learning, Memory, \& Cognition, 17, 245262.

Gernsbacher, M. A., Keysar, B., Robertson, R. R. W., \& Werner, N. K. (2001). The role of suppression and enhancement in understanding metaphors. Journal of Memory \& Language, 45, 433-450.

GlenberG, A. M., Meyer, M., \& Lindem, K. (1987). Mental models contribute to foregrounding during text comprehension. Journal of Memory \& Language, 26, 69-83.

Graesser, A. C., Singer, M., \& Trabasso, T. (1994). Constructing inferences during narrative text comprehension. Psychological Review, 101, 371-395.

HaKaLA, C. M. (1999). Accessibility of spatial information in a situation model. Discourse Processes, 27, 261-279.

Hess, D. J., Foss, D. J., \& Carroll, P. (1995). Effects of global and local context on lexical processing during language comprehension. Journal of Experimental Psychology: General, 124, 62-82.

Johnson-LAIRD, P. N. (1983). Mental models: Towards a cognitive science of language, inference, and consciousness. Cambridge, MA: Harvard University Press.

Johnson-Laird, P. N. (1989). Mental models. In M. I. Posner (Ed.), Foundations of cognitive science (pp. 469-499). Cambridge, MA: Harvard University Press.

KINTSCH, W. (1988). The role of knowledge in discourse comprehension construction-integration model. Psychological Review, 95, 163182.

KUČERA, J., \& FrANCIS, W. N. (1967). Computational analysis of presentday American English. Providence, RI: Brown University Press.

Langston, W., Kramer, D. C., \& GlenberG, A. M. (1998). The representation of space in mental models derived from text. Memory \& Cognition, 26, 247-262.

Levine, W. H., \& KLIN, C. M. (2001). Tracking of spatial information in narratives. Memory \& Cognition, 29, 327-335.

Linderholm, T., Gernsbacher, M. A., van den Broek, P., Neninde, L., Robertson, R., \& Sundermeier, B. (2004). Suppression of story character goals during reading. Discourse Processes, 37, 67-78.

LuTZ, M. F., \& RadvansKy, G. A. (1997). The fate of completed goal information in narrative comprehension. Journal of Memory \& Language, 36, 293-310.

Magliano, J. P., \& Graesser, A. C. (1991). A three-pronged approach method for studying inference generation in literary text. Poetics, 20, 193-232.

Morrow, D. G., Bower, G. H., \& Greenspan, S. L. (1989). Updating situation models during comprehension. Journal of Memory \& Language, 13, 441-469.

Morrow, D. G., Greenspan, S. L., \& Bower, G. H. (1987). Accessibility and situation models in narrative comprehension. Journal of Memory \& Language, 26, 165-187.

Morrow, D. G., Leirer, V., Altieri, P., \& Fitzsimmons, C. (1994). Age differences in creating spatial models from narratives. Language \& Cognitive Processes, 9, 203-220.

Myers, J. L., \& O'Brien, E. J. (1998). Accessing the discourse representation during reading. Discourse Processes, 26, 131-157.

Myers, J. L., O’Brien, E. J., Albrecht, J. E., \& Mason, R. A. (1994). Maintaining global coherence during reading. Journal of Experimental Psychology: Learning, Memory, \& Cognition, 20, 876-886.

O’Brien, E. J., \& Albrecht, J. E. (1992). Comprehension strategies in the development of a mental model. Journal of Experimental Psychology: Learning, Memory, \& Cognition, 18, 777-784. 
O’Brien, E. J., Raney, G. E., Albrecht, J. E., \& Rayner, K. (1997). Processes involved in the resolution of explicit anaphors. Discourse Processes, 23, 1-24.

OMANSON, R. C. (1982). The relation between centrality and story category variation. Journal of Verbal Learning \& Verbal Behavior, 21, 326-337.

Perfetti, C. A. (1989). There are generalized abilities and one of them is reading. In L. B. Resnick (Ed.), Knowing, learning, and instruction: Essays in honor of Robert Glaser (pp. 307-335). Hillsdale, NJ: Erlbaum.

Pressley, M., \& Afflerbach, P. (1995). Verbal protocols of reading: The nature of constructively responsive reading. Hillsdale, NJ: Erlbaum.

Radvansky, G. A., \& Copeland, D. E. (2000). Functionality and spatial relations in memory and language. Memory \& Cognition, 28, 987-992.

Radvansky, G. A., Zwahn, R. A., Curiel, J. M., \& Copeland, D. E. (2001). Situation models and aging. Psychology \& Aging, 16, 145160.

RATCLIFF, R. (1993). Methods for dealing with reaction time outliers. Psychological Bulletin, 114, 510-532.

RINCK, M., \& Bower, G. H. (1995). Anaphora resolution and the focus of attention in situation models. Journal of Memory \& Language, 34, $110-131$.

Trabasso, T., \& Magliano, J. P. (1996). Conscious understanding during comprehension. Discourse Processes, 21, 255-287.

Trabasso, T., \& Sperry, L. L. (1985). Causal relatedness and importance of story events. Journal of Memory \& Language, 24, 595-611.

Trabasso, T., \& SuH, S. Y. (1993). Understanding text: Achieving explanatory coherence through on-line inferences and mental operations in working memory. Discourse Processes, 16, 3-34.

Trabasso, T., \& Van den Broek, P. (1985). Causal thinking and the representation of narrative events. Journal of Memory \& Language, 24, 612-630.

vaN DEN Broek, P. (1990). The causal inference maker: Towards a process model of inference generation in text comprehension. In D. A. Balota, G. B. Flores d'Arcais, \& K. Rayner (Eds.), Comprehension processes in reading (pp. 423-445). Hillsdale, NJ: Erlbaum.

VAN DEN BRoEK, P. (1994). Comprehension and memory of narrative texts: Inferences and coherence. In M. A. Gernsbacher (Ed.), Handbook of psycholinguistics (pp. 539-588). San Diego: Academic Press.

VAN DEN BROEK, P., \& LORCH, R. F., JR. (1993). Network representations of causal relations in memory for narrative texts: Evidence from primed recognition. Discourse Processes, 16, 75-98.

van den Broek, P., Young, M., Tzeng, Y., \& Linderholm, T. (1999). The landscape model of reading: Inferences and the on-line construction of a memory representation. In H. van Oostendorp \& S. R. Goldman (Eds.), The construction of mental representations during reading (pp. 71-98). Mahwah, NJ: Erlbaum. van Disk, T. A., \& Kintsch, W. (1983). Strategies in discourse comprehension. New York: Academic Press.

Wilson, S. G., Rinck, M., McNamara, T. P., Bower, G. H., \& MorRow, D. G. (1993). Mental models and narrative comprehension: Some qualifications. Journal of Memory \& Language, 32, 141-154.

Wolman, C., \& van den Broek, P. (1993). Comprehension and memory for narrative texts by mentally retarded and learning disabled children. Unpublished manuscript.

Zwaan, R. A., Langston, M. C., \& Graesser, A. C. (1995). The construction of situation models in narrative comprehension: An eventindexing model. Psychological Science, 6, 292-297.

Zwaan, R. A., Magliano, J. P., \& Graesser, A. C. (1995). Dimensions of situation model construction in narrative comprehension. Journal of Experimental Psychology: Learning, Memory, \& Cognition, 21, 386-397.

ZwaAn, R. A., \& RAdVAnsky, G. A. (1998). Situation models in language comprehension and memory. Psychological Bulletin, 123, $162-185$.

Zwaan, R. A., Radvansky, G. A., Hilliard, A. E., \& Curiel, J. M. (1998). Constructing multidimensional situation models during reading. Scientific Studies of Reading, 2, 199-220.

Zwahn, R. A., van den Broek, P., Truitt, T. P., \& Sundermeier, B. (1996). Causal coherence and the accessibility of object locations in narrative comprehension. Abstracts of the Psychonomic Society, 1, 50 .

Zwaan, R. A., \& van Oostendorp, H. (1993). Do readers construct spatial representations during naturalistic comprehension? Discourse Processes, 16, 125-143

ZWAan, R. A., \& VAN OOSTENDORP, H. (1994). Spatial information and naturalistic story comprehension. In H. van Oostendorp \& R. A. Zwaan (Eds.), Naturalistic text comprehension (pp. 97-114). Norwood, NJ: Ablex.

\section{NOTES}

1. Two additional experiments were conducted in which speed was emphasized more than accuracy in the instructions to the participants. There was a significant $(10 \%)$ difference in accuracy rates to targets in experimental versus control conditions when they were probed after the critical sentence. When they were probed before the critical sentence, there was a nonsignificant (1\%) difference in accuracy rates between experimental and control conditions. In these experiments, there were no significant differences in response times. These results for accuracy provide convergent evidence for those obtained for response times in Experiments $2 \mathrm{~A}$ and $2 \mathrm{~B}$.

2. We thank Arthur Glenberg for suggesting this possibility.

3. The difference in response times to targets presented before and after the outcome sentences in the control (noncausal) version was not significant (all $t \mathrm{~s}<1)$. 


\section{APPENDIX \\ Sample Story Used in All the Experiments}

It was a crisp morning with a chill in the air and frost on the trees. However, the sun was bright and streaming through the window of the Nielsens' bedroom. The light shone on Mark, whose sleep was being greatly disturbed by this dawn, and his eyes were forced to open and greet a new day. Now Mark couldn't help smelling the scent of bacon and toast downstairs. As he looked to a bundle of empty sheets next to him, he realized that his wife June was preparing breakfast. The couple chatted while they ate and soon Mark realized he had to go to work. At work, Mark quickly dodged into his office to get away from the crowd. He was surprised to see someone in his chair. It was Gena, and the two talked about their plans to go out to this exquisite restaurant and then a play tonight. The date was set. After eating lobster at the restaurant, Gena and Mark went to Macbeth. They entered the large auditorium, got their reserved tickets at the counter, and headed to the doors.

[Control version:]

Mark stuffed his gloves in his pants pocket so that he could have both hands free to help Gena take off her beautiful shiny fur. Gena put their ticket stubs in her purse.

[Causal version:]

Mark stuffed their ticket stubs in his pants pocket so that he could have both hands free to help Gena take off her beautiful shiny fur. Gena put her gloves into her purse.

Then they took a seat near the middle of the theater. The play was excellent. Exhausted by a long day at work followed by this cultural experience, Mark and Gena parted ways, kissed passionately, and went to their homes. The next morning was frigid and foggy. The sun did not awaken Mark.

[PROBE BEFORE]

Instead, he was startled by his wife's voice coming from the laundry room which was getting closer and closer, "Mark, you are seeing another woman!"

[PROBE AFTER]

$* * *$ pocket $* * *$ [location probe]

$* * *$ ticket $* * *$ [object probe]

Question: Did Mark and Gena spend the night together?

Note-Location probes were used in Experiments 1,2A, and 2B. Object probes were used in Experiments 3A and $3 \mathrm{~B}$. The critical sentences are italicized here only for purposes of illustration.

(Manuscript received December 11, 2002;

revision accepted for publication June 28,2004 .) 